\title{
Design and mixing performance characterization of a mini-channel mixer with nature-inspired geometries
}

\author{
Dominique Tarlet ${ }^{\mathrm{a}, 1}$, Yilin Fan ${ }^{\mathrm{a}}$, Lingai Luo ${ }^{\mathrm{a}}$ \\ ${ }^{a}$ Université de Nantes, CNRS, Laboratoire de thermique et énergie de Nantes, LTeN, \\ UMR 660\%, F-44000 Nantes, France.
}

\begin{abstract}
This study proposes a new design of milli- or micro-mixers based on the split-intersect-recombine principle. The vascular flow topology mimics the respiratory or circulatory architectures existing in nature, including tree-like bifurcated networks and meshed flow circuit. Special focus is given to the enhancement of mixing performance by fluid collisions and flow deviations at the intersections of the meshed circuit. To do that, an optical tracer is added in one of the fluids to be mixed and its progression is monitored and recorded by a high-definition CCD camera. The mixing efficiency of the meshed circuit is then characterized by the evolution of the tracer's local concentration profiles based on the Beer-Lambert absorption. Experimental results obtained show that compared to straight channels, the mixing performance can be improved by about $20 \%$ owing to the numerous flow intersections in the meshed circuit. Moreover, the viscosity difference between two fluids to be mixed has a positive effect on the mixing performance by augmenting the chance of flow deviation from one stream into another at the crossroads. An optimum performance can be noticed in the form of a plateau of the estimated shear stress.
\end{abstract}

Keywords: Mixer, Nature-inspired, Concentration profile, Difference in viscosities, Meshed circuit, Split-intersect-recombine

Email address: dominique.tarlet@univ-nantes.fr (Dominique Tarlet)

${ }^{1}$ corresponding author 


\section{Nomenclature}

\begin{tabular}{|c|c|c|}
\hline Variable & Meaning & Units \\
\hline$A$ & Absorbance & - \\
\hline$B_{i}$ & Blue component & - \\
\hline$C$ & Molar concentration & mol.L $L^{-1}$ \\
\hline $\bar{C}$ & Mean molar concentration & mol.L $\mathrm{L}^{-1}$ \\
\hline$C_{i}$ & Concentration field & $\mathrm{mg} \cdot \mathrm{L}^{-1}$ \\
\hline$D$ & Mass diffusivity & $\mathrm{m}^{2} \cdot \mathrm{s}^{-1}$ \\
\hline$D_{h}$ & Hydraulic diameter & $\mathrm{m}$ \\
\hline$L^{*}$ & Non-dimensional length & - \\
\hline$M_{X}$ & Mixing efficiency & - \\
\hline$M_{X}^{*}$ & Mixing efficiency & - \\
\hline$n$ & Number of pixels & - \\
\hline$P$ & Pressure & bar \\
\hline$Q_{V}$ & Volume flow rate & $\operatorname{mL} \cdot \min ^{-1}$ \\
\hline$R e$ & Reynolds number & - \\
\hline$S$ & Section area & $m^{2}$ \\
\hline$V_{\text {in }}$ & Void volume for fluids & $\mathrm{m}^{3}$ \\
\hline$V_{q}$ & Flow velocity & $\mathrm{m} . \mathrm{s}^{-1}$ \\
\hline$W_{q}$ & Energy dissipation rate & $\mathrm{W} \cdot \mathrm{kg}^{-1}$ \\
\hline$X$ & Distance & $\mathrm{m}$ \\
\hline
\end{tabular}

\begin{tabular}{lcc} 
Variable & $\begin{array}{c}\text { Meaning } \\
\text { Greek symbols }\end{array}$ & Units \\
\hline$\Delta P$ & Pressure drop & $\mathrm{Pa}$ \\
$\epsilon$ & Molar absorptivity & $\mathrm{L} \cdot \mathrm{mol}^{-1} \cdot \mathrm{m}^{-1}$ \\
$\mu$ & Dynamic viscosity & $\mathrm{Pa} \cdot \mathrm{s}$ \\
$\rho$ & Density & $\mathrm{kg} \cdot \mathrm{m}^{-3}$ \\
& & \\
\hline$w$ & Subscripts & - \\
0 & Water & - \\
$\infty$ & Before any mixing & -
\end{tabular}




\section{Highlights}

- A new milli-channel mixer is proposed and tested for well-controlled mixing.

- The design is based on the split-intersect-recombine principle with nature-inspired geometries.

- An optical, easy-to-implement measurement of the tracer's local concentration profiles is carried out.

- Fluid collision at the numerous intersections of the meshed circuit enhances the mixing.

- A critical value of shear rate that favours the flow deviation is figured out.

\section{Introduction}

Well-controlled mixing process within a milli-sized or micro-sized channel is widely used to handle sensitive chemical reactions Woldemariam et al. (2016), for the purpose of chemical or biochemical analysis Roder et al. (2006); Alemàn et al. (2008) or nanomaterials synthesis deMello and deMello (2004). Generally, it is used to better monitor the reaction kinetics that starts when reagents are actually mixed and their molecules are in close contact Hertzog et al. (2006). This is the reason why mixing process has to be carried out swiftly and efficiently Egawa et al. (2009); Gambin et al. (2010); Mao et al. (2010).

Based on the spatial scales, the mixing of liquids can be categorized into macro-mixing, meso-mixing and micro-mixing, each governed by its proper mechanisms and corresponding driving forces Ottino (1989). Macro-mixing happens by the spatial movement of fluid, characterized by the convective flow and the turbulences. Meso-mixing happens between the interface of two liquids, where the viscous or shear stress can stretch the fluids and force them to be mixed. The mechanism for micro-mixing is mainly the molecular Brownian movement, usually described as a diffusion. Since all the above mentioned mechanisms determine the mixing performance in a cascade manner Schwertfirm et al. (2007), the actual design of mixers should try to enhance all the three scales to reduce the overall mixing time and to intensify the mass transfer. Particularly for milli- or micro mixers that are 
usually operated under laminar flow regime due to small channel dimensions, various geometric considerations were taken into account through optimization so as to enhance the meso and micromixing Chen et al. (2016); Chen and Li (2017). For example, modified T-type mixers, E-shape micromixers Chen and Shen (2017), lamination-based micromixers, obstacle-based micromixers and staggered herringbone micromixers Chen and Wang (2015); static and chaotic micromixers have been constructed and their mixing performances have been well demonstrated Lee et al. (2016); Bayareh et al. (2020).

Recently, the design of mixers having nature-inspired geometries has also received increasing attention. One of the typical categories mimics the respiratory or circulatory systems of live organisms, in the sense that fluids are firstly divided into several small streams and then joined together downstream Cieslicki and Piechna (2009). This vascular flow topology is reported to be capable of treating high throughput mixing flows with high spatial nonhomogeneities in their composition at the cost of an acceptable pressure drop Ghanem et al. (2014); Gray et al. (1999); Neerincx et al. (2011); Chen et al. (2011). The advantages are threefold. Firstly, since the time of diffusion is proportional to the square of the diffusion distance, a splitting of large stream into $n$ small laminae could accelerate the micro-mixing by a factor up to $n^{2}$ Erbacher et al. (1999); Suh and Kang (2010). Secondly, the surface area of the two fluids in contact, i.e. the interface, could also be multiplied. Finally, the multiple collisions and flow impingements caused by the recombination of small streams into a unique channel further enhance the mixing Guo et al. (2013).

Among other applications such as self-sorting of microbeads and cells Lee et al. (2009); Choi et al. (2009), biomimetically designed micro-mixers usually apply the Murray's scaling law within their successive bifurcations of the flow Huang et al. (2009). In order to precisely bound this field of biomimetics, Lee (2000) reminds that it consists in microchannels with a cylindrical cross-section mimicking micro-vascular networks from arterioles and venules $(8-250 \mu \mathrm{m})$ to small arteries and small veins $(0.25-2 \mathrm{~mm})$. As an example, this range of size matches the smallest vessels in the liver which play a critical role in the transportation of a small number of molecules to and from the blood stream, respectively Jang et al. (2015). The identified Murray's law has a slightly different exponent in larger vessels closer to the base of arterial trees Huang et al. (2009); Tondeur et al. (2009). To produce 3D nature-inspired geometries presenting a high level of complexity, specific fabrication processes like stereolithography Tarlet et al. (2014); Ching et al. 
(2019), irradiated PMMA resin Huang et al. (2009) or milled PDMS Jang et al. (2015) are intensively used.

The present study proposes a new split-intersect-recombine design of milli- or micro-mixers based on nature-inspired architectures. Firstly, a multi-scale tree-like network is intended to deliver and split a certain quantity of fluid from a single inlet to a series of small streams, and vice versa for the recombining. The bifurcation topology is able to guarantee the same flow paths and conditions for each of the distributed channels, i.e., the residence time and the flow rate are expected to be identical in each of them Yue et al. (2010); Zhou et al. (2018). Secondly, meshed circuit inspired by the land crack architecture in nature connects the split part and the recombine part Tondeur et al. (2011a,b). Compared to the simple straight channels counterpart, enhanced mixing is expected owing to the frequently happened fluid collision at the numerous intersections of the meshed circuit.

Regarding the multi-scale tree-like network, the flow-rate equipartition feature when used as fluid distributor under laminar flow conditions Zhou et al. (2017); Barber and Emerson (2008); Wang (2007) and the mixing enhancement when used as fluid collector Guo et al. (2013); Cieslicki and Piechna (2009) have been well demonstrated in earlier studies. The present study is thus focused on the meshed circuit with the purpose of characterizing the mixing performance enhancement by fluid collisions and flow deviations at the intersections.

To quantify the local mixing efficiency, one of the possible methods is to add an optical tracer in one of the fluids to be mixed and optically measure the local concentration profiles of the tracer Aubin et al. (2010); Hsieh et al. (2013). Inhomogeneity of the concentration field indicates an incomplete mixing, whereas a perfectly achieved mixing results in a totally homogeneous concentration field. In this study, the fluorescein is used as the tracer and its concentration field is measured by means of Beer-Lambert absorption. The local mixing efficiency is then quantified covering all channels of the meshed circuit part. Complete mixing has been achieved in some cases at the end of the meshed circuit part, especially when the viscosities of the two liquids are different. 


\section{Experimental set-up and methodology}

\subsection{Nature-inspired mixer}

The design of the mixing device is based on the split-intersect-recombine principle comprising of nature-inspired geometries, as shown in Fig. 1. The first step is the equal splitting of both fluids from their single inlet port (diameter $3 \mathrm{~mm}$ ) into 8 sub-streams through multi-scale bifurcated distributors. The natural curved tree shape is a result of structural optimization realized by a numerical algorithm developed in house Wang et al. (2010, 2014). In this tree-like network, the channel depth equals to $1 \mathrm{~mm}$ and the channel widths of the successive branches are listed in Tab. 1. The sub-streams of both fluids to be mixed are then guided into the meshed circuit having channel interlacing, all channels having a rectangular cross-section of $1.1 \mathrm{~mm}$ in width and $1 \mathrm{~mm}$ in depth. Collision happens at each channel intersection at a crossing angle of $60^{\circ}$. Finally, a multi-scale bifurcated collector recombines the sub-streams of mixture from the 16 endpoints of the meshed circuit to the global outlet port. The multiple collisions resulted from the recombining of the fluids in the multi-scale collector can provide efficient and supplementary fluid interactions towards a complete mixing at the global outlet Guo et al. (2013). Another example of split-intersect-recombine geometry among the scientific literature (inspired from vascular topology) is also shown in Fig. 1.

Another configuration having parallel straight channels (cross-section: 1.1 $\mathrm{mm} \times 1.0 \mathrm{~mm}$ ) instead of meshed circuit is also introduced for comparison (shown in Fig. 4). The mixture from Y-type junctions flows directly to parallel straight channels and then to the collector. The testing of this conventional split-recombine design will highlight the effect of channel intersecting on the enhancement of the mixing performance.

\begin{tabular}{|c|c|}
\hline \multicolumn{2}{|c|}{ Rectangular channel sections } \\
\hline Depth & $1 \mathrm{~mm}$ \\
\hline Width & {$[3.28,2.65,1.8,1.1] \mathrm{mm}$} \\
\hline
\end{tabular}

Table 1: Dimensions of the branches of the tree-like network.

The manufacturing of the mixer prototypes by laser stereolithography has been realised at the LTeN laboratory using the FORMLABS Form 1+ / Form 2 3-D printer. Transparent resin FLGPCL03 was used. Once produced by the 3 -D printer, the external surfaces of the prototypes were swept using a 


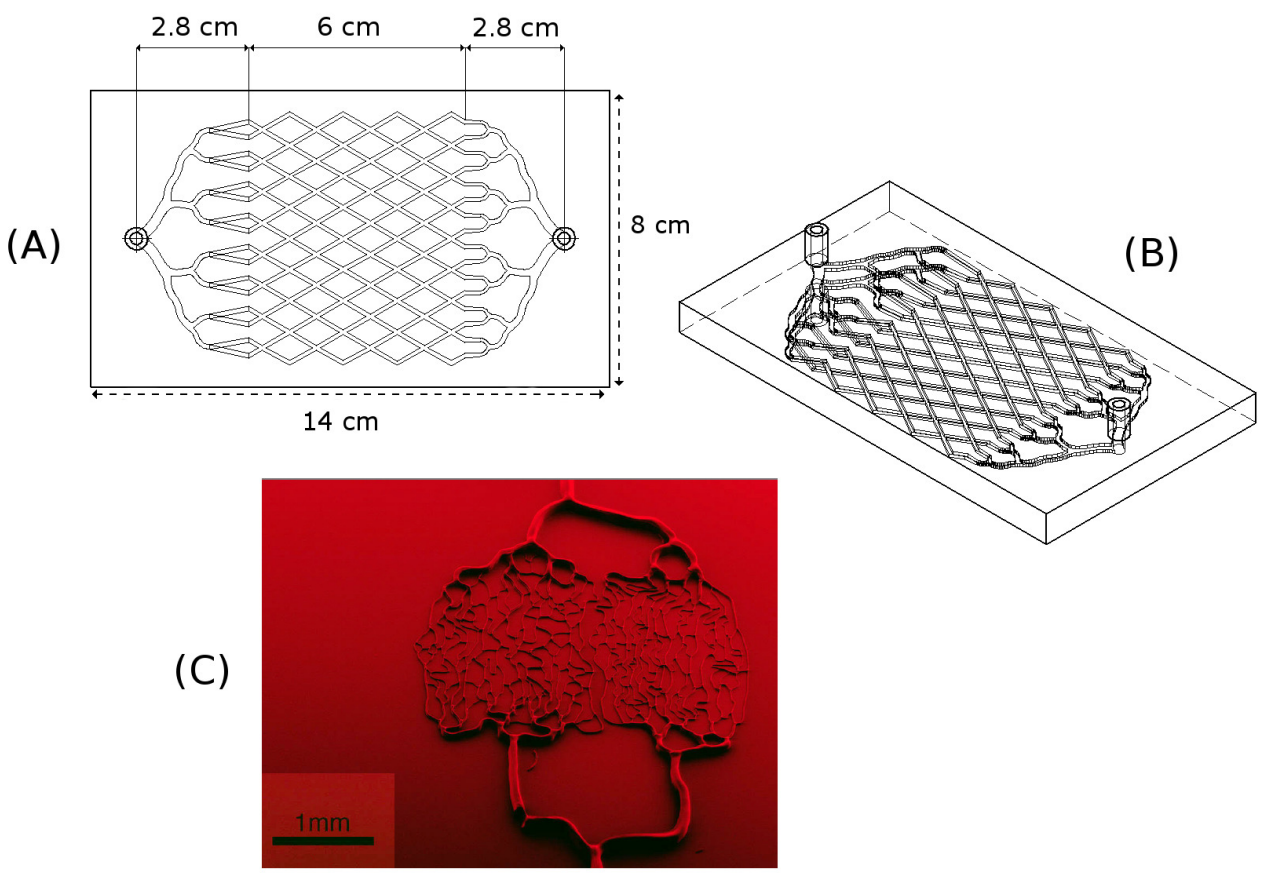

Figure 1: Schematic view of the split-intersect-recombine mixing device with natureinspired geometries - (A): Front view; (B) Isometric view; (C) Vascular topology Montpellier, reproduced with permission of Benoit Charlot @IES (CNRS/Université de Montpellier), 2018. 


\begin{tabular}{lccccc}
\hline Liquids at $25{ }^{\circ} \mathrm{C}$ & Water & \multicolumn{4}{c}{ Glycerine (\% vol.) } \\
\cline { 3 - 6 } & & 11.1 & 5 & 2.5 & 0.25 \\
\hline$\mu[\mathrm{mPa} . \mathrm{s}]$ & 1 & 1.2 & 1.09 & 1.045 & 1.0045 \\
$\rho\left[\mathrm{kg} . \mathrm{m}^{-3}\right]$ & 998 & 1003 & 1001 & 1000 & 1000 \\
Supplier & Tap water & \multicolumn{4}{c}{ Chemlab } \\
\hline
\end{tabular}

Table 2: Physical properties of the used fluids.

piece of cotton and Abel Industries polishing agent until good transparency has been achieved for optical measurement.

\subsection{Experimental set-up and working fluids}

The experimental setup is shown in Fig. 2. The mixing device was oriented vertically (i.e. horizontal metal rail) during experiments with water at both sides (section 3.1). Due to buoyancy effects, it was placed horizontally (i.e. vertical metal rail) during experiments with different viscosities reported in section 3.3. Both liquids were fed into the inlets of the mixer prototype by KDS syringe pushers (KDS-100-CE and Legato 110, with uncertainty +/$0.05 \mathrm{~mL} \cdot \mathrm{h}^{-1}$ ), ensuring a good stability of the liquid feeding flow rate. The tested liquid flow rate ranged between $3.1 \mathrm{~mL} . \mathrm{h}^{-1}$ and $25 \mathrm{~mL} . \mathrm{h}^{-1}$, corresponding to an average Reynolds number from 0.1 to 0.8 in every $1 \mathrm{~mm} \times$ $1.1 \mathrm{~mm}$ branches of the meshed circuit. Two pressure sensors (KELLER LEO-3, measuring range 0-4 bar, precision 1 mbar) were installed to monitor the pressure at each inlet of the mixer. The mixture of the two liquids was collected from the outlet port on top of the mixer at the atmospheric pressure. To ensure the steady state of the fluid flow, the constant flow rates were maintained during 5 minutes before measurements were started. The CCD camera and the light source were also attached on the same metal rail as for the mixer where their axial positions could be adjusted and clamped, so as to guarantee reproducible experimental conditions and optical focus. Good reproducibility of the measurement under different tested conditions was observed.

Tap water was used as the working liquid while different amounts of glycerine from 0.1 to $11.1 \%$ vol. were added in water to modify its viscosity. Tab. 2 lists the physical properties of the tested liquids measured at $25^{\circ} \mathrm{C}$. The liquid viscosity was measured by a LAMY RM-200 rheometer with its attached uncertainty of $1 \%$. 


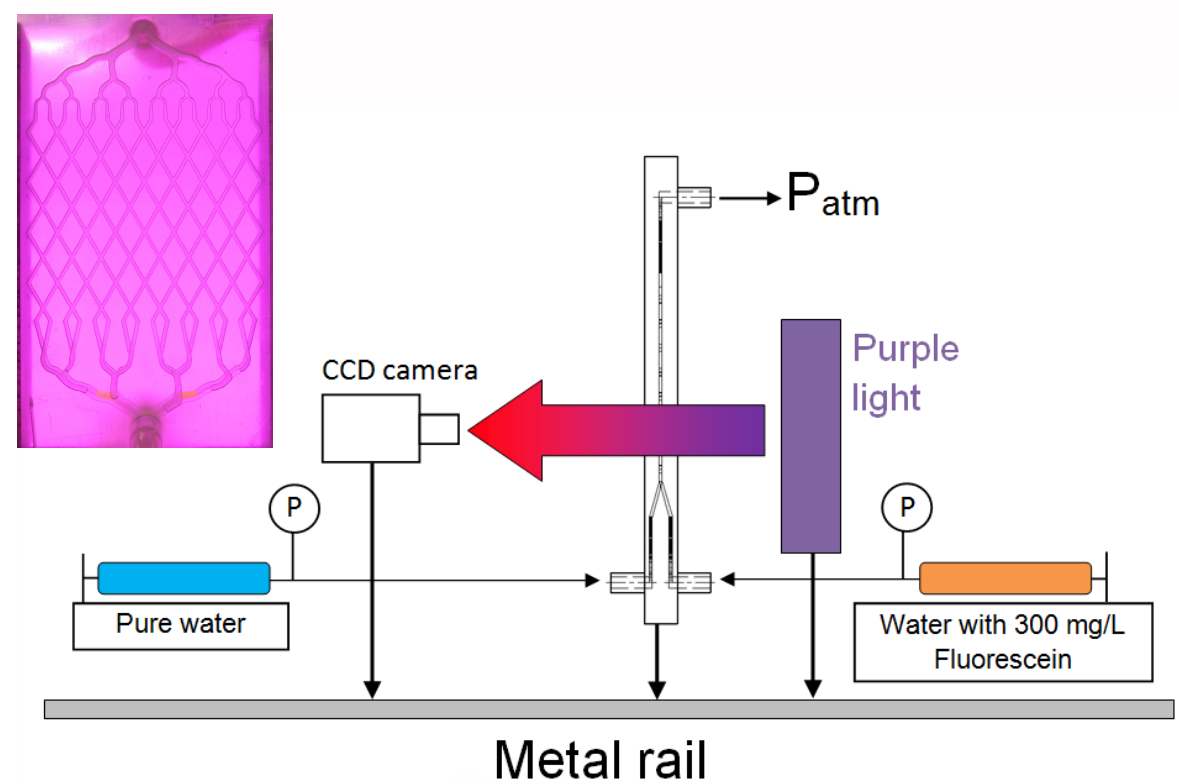

Figure 2: Schematic of the experimental setup for the measurement of concentration profiles. An actual picture of the mixing device is inserted. 
To examine the possibility of an effective mixing process, a rapid comparison is suggested by Woldemariam et al. (2016). Considering water mass diffusivity $D=2.3 .10^{-9} \mathrm{~m}^{2} \cdot \mathrm{s}^{-1}$ across half of the channel width $(\simeq 0.55$ $\mathrm{mm}$ ) gives the diffusional time scale as long as $132 \mathrm{~s}$ that can be compared to the residence time in the meshed circuit (not including distributor and collector) estimated between $667 \mathrm{~s}$ and $76 \mathrm{~s}$ at 3.1 and $25 \mathrm{~mL} \cdot \mathrm{h}^{-1}$ in both feeding inlets, respectively. But the fluids are not always in contact with each other, except at the crossroads. The residence time and the diffusional time scale have nearly the same order of magnitude, so the enhancement in the form of flow deviation and shear stress had to be implemented beside molecular diffusion, which will be further discussed later.

\subsection{Measurement of concentration profiles in the meshed circuit}

To understand the effect of channel intersecting on the transport properties, the mixing has been studied by measuring the local concentration field within the channels and the intersects of the meshed circuit. Concentration of the fluorescein that gives water a bright green-yellow colour was measured through Beer-Lambert absorption Li et al. (2012); Hsieh et al. (2013); Woldemariam et al. (2016). It enables a non-intrusive measurement of the local concentration field, for the characterization of the local mixing performance. The LED panel LEDP (JAGO AG Stuttgart $48 \mathrm{~W}, 115 \times 25 \mathrm{~cm}$ ) is much larger than the mixing device to provide a homogeneous enlightenment over the whole surface. It is covered with a purple plastic film (SATEMO SARL Company, filmpourvitrage.com) to illuminate the transparent meshed circuit device from behind, providing purple (blue and red) light. At the opposite side of the device, the absorption of the blue light by the fluorescein was measured by a high-definition CCD LUMIX DMC TZ 60 camera $(4896 \times 3672$ pixels) that gives the blue component of the obtained image with 18 million of pixels. The white balance and exposure level of the camera were predefined and kept the same in all the experiments. Finally, the concentration field $C_{i}$ in the channels and intersections of the meshed circuit (excluding the distributors and the collector) is composed of a number of pixels $n$ around 3.1 million, each pixel having a side of about $21 \mu \mathrm{m}$.

According to the well-known Beer-Lambert theory Parnis and Oldham (2013) the absorbance $A$ of the blue light across the channel is proportional to the concentration in fluorescein, as expressed by Eq. 1 where $\epsilon$ is molar absorptivity, $X$ the length of the beam through the solution and $C$ the concentration. An experimental calibration of this optical method has been 
performed by filling the channel with water having a known concentration of fluorescein. The blue component $B_{i}$ (value between 0 and 255) of the JPEG image issued from the CCD camera as a function of the concentration is plotted and shown as the inserted picture on Fig. 3.

$$
A=\epsilon X C
$$

The concentration measurement using a high-definition camera enables the non-intrusive characterization of the mixing progress all along the successive sections, as illustrated for example in Fig. 3. The two streams were fed with each $15 \mathrm{~mL} . \mathrm{h}^{-1}$ flow rate, one having $300 \mathrm{mg} . \mathrm{L}^{-1}$ of fluorescein, and the other without the dye. The higher concentration of fluorescein appears reddish in the raw image while pure water appears purple (A). The image (B) shows the blue component of the image, and Beer-Lambert absorption makes it much lower where a higher concentration of fluorescein is present on the raw image (A). Finally, in the image of the concentration field (C) one can see the mixing being progressively achieved along the successive intersections of the meshed circuit. In the end, all the channels are of the intermediate color, i.e. half concentration, which is interpreted as the complete mixing. The obtained concentration field $C_{i}$ was treated by 2-D median filtering (MatlabImage Processing Toolbox) and smoothing of the data to remove the noise. To obtain the value of $C_{i}$, image acquisition was performed in a dark room by the DMC TZ-60 camera and computational post-treatment included the chosen calibration formula. Considering the dispersion of $C_{i}$ values using every fitting calibration formula, the uncertainty range was observed as less than $5 \%$. A relative uncertainty of $C_{i}$ was thus estimated as $\pm 2.5 \%$, taking into account the image acquisition, the Beer-Lambert calibration and the computational post-treatment.

\subsection{Indicators and dimensionless numbers}

Different indicators and dimensionless parameters are used to describe the liquid flow properties and its interactions along with the mixing process. The Reynolds number Re (Eq. 2) is less than 1 in the meshed circuit under

the present tested conditions. Chen et al. (2011) found that the molecular diffusion is dominant over advective transport in a split-and-recombine mixing flow for a $R e$ number between 0.5 and 50 .

$$
R e=\frac{\rho D_{h} V_{q}}{\mu}
$$




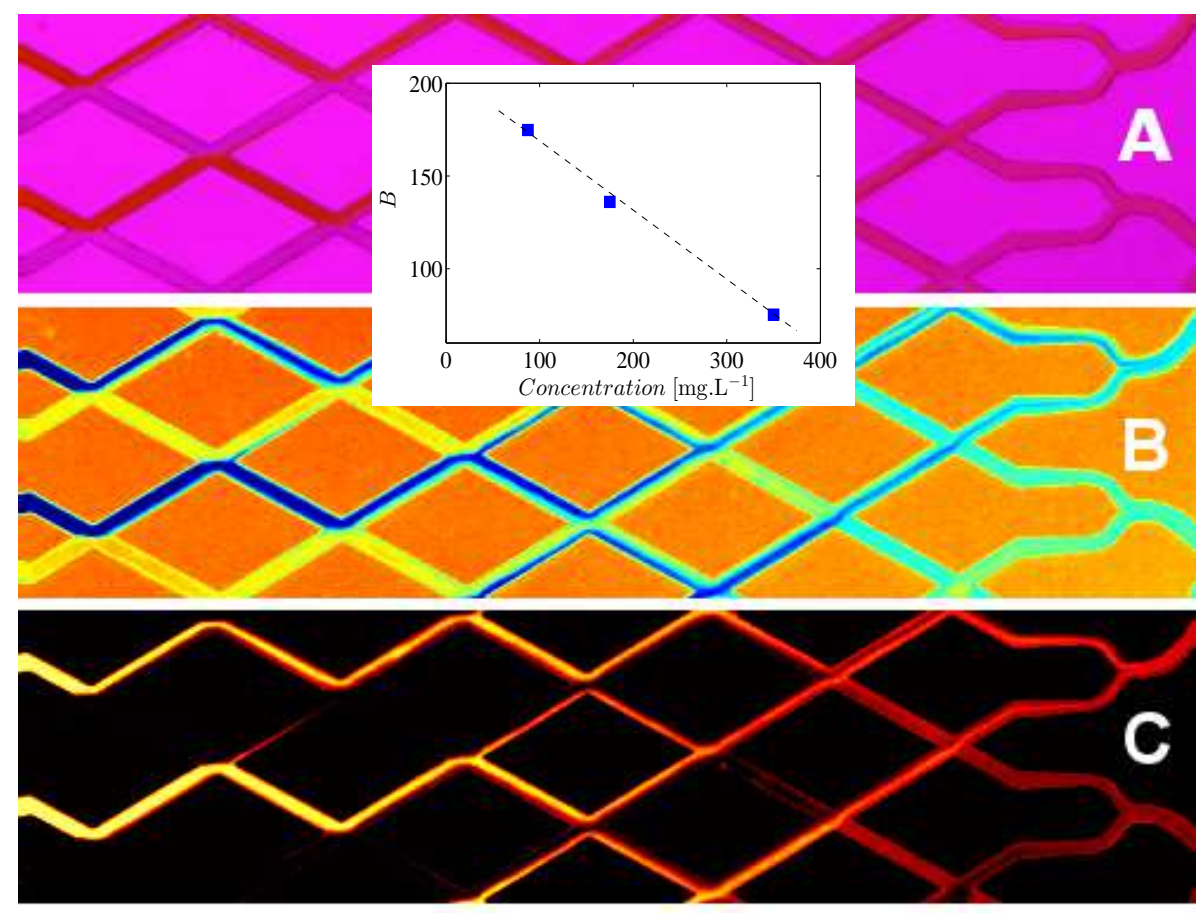

Figure 3: The three steps of the concentration measurement. (A): Raw image of the two fluid streams with and without fluorescein. (B): Blue component of the image A. (C): Concentration of fluorescein calculated based on the Beer-Lambert law. Channel width: $1.1 \mathrm{~mm}$, channel depth: $1 \mathrm{~mm}$, flow rate: twice $15 \mathrm{~mL} \cdot \mathrm{h}^{-1}$, superficial velocity: 4.7.10 ${ }^{-4} \mathrm{~m} . \mathrm{s}^{-1}$ - Inserted picture: Calibration of the Beer-Lambert law of absorption (Blue component $[0-255])$. 
The mixing efficiency $M_{X}$ (Eq. 3) is calculated based on the extended concentration field $C_{i}$ and its mean value $\bar{C}$. The value of $M_{X}$ is 1 in the theoretical case of perfectly homogeneous concentration and decreases when the concentration field becomes inhomogeneous due to the worse mixing of two fluids. Because the relative uncertainty of the concentration field $C_{i}$ is $\pm 2.5 \%$, propagation of uncertainty gives the relative uncertainty of $M_{X}$ as high as $\pm 5 \%$.

$$
M_{X}=1-\frac{1}{\bar{C}}\left[\frac{\sum_{1}^{n}\left(C_{i}-\bar{C}\right)^{2}}{n}\right]^{\frac{1}{2}}
$$

Taking into account real-world measurements imperfections and elimination of the background noise, a value of $M_{X}$ exceeding $85 \%$ is considered here as a complete mixing. In numerical studies reviewed by Lee et al. (2016), a different formulation of the mixing index $M_{X}^{*}$ (Eq. 4) is used, where $C_{0}$ and $C_{\infty}$ are the values of concentration before any mixing and with complete mixing respectively. In the case of complete mixing, the best mixing performance is 86\% Ansari and Kim (2010) and 83\% Afzal and Kim (2015).

$$
M_{X}^{*}=\left(1-\frac{\sum_{1}^{n}\left|C_{i}-C_{\infty}\right|}{\sum_{1}^{n}\left|C_{0}-C_{\infty}\right|}\right) \times 100 \%
$$

\section{Results and discussion}

\subsection{Mixing performance of the meshed circuit}

The measured concentration fields in the channels of the meshed circuit with different feeding flow rates are shown in Fig. 4. Note that identical liquid flow-rates were fed in both inlets of the mixer, one with fluorescein dye and the other not. At the entry of the meshed circuit (the flow goes from the left to the right in Fig. 4), a part of the highly concentrated flow is deviated into the pure water, as it is visible in (A) at the lower flow rate $\left(4.3 \mathrm{~mL} \cdot \mathrm{h}^{-1}\right.$ each). This flow deviation enables a good mixing, as color change of the pure water can be rapidly seen dowstream. When the flow rate is increasing (B; 8.8 $\mathrm{mL} \cdot \mathrm{h}^{-1}$ each), this phenomenon of deviated flow is less pronounced despite successive intersections and only a small quantity of fluorescein dye enters into the pure water. At the highest flow rate tested (C; $18.8 \mathrm{~mL} \cdot \mathrm{h}^{-1}$ each), no obvious mixing effect can be seen. The flow of pure water remains apart with almost no intrusion of highly concentrated fluorescein stream all along 
the trajectory. To sum up, the lower velocity favours to deviate a part of the highly concentrated fluorescein stream into the pure water from the first stage of the meshed circuit, drastically improving the mixing performance.

Fig. 4D shows a case of straight channel for comparison. The shear stress is not enhanced except at the single Y-junction. In these straight mixing channels, the two streams can be seen flowing side-by-side and the mixing is mainly due to the molecular diffusion. A homogeneous concentration field can not be achieved at the end of the straight channels before entering into the multi-scale tree-like collector.

The progression of the local mixing efficiency $M_{X}$ within the meshed circuit (every 10\% of its total length) is shown in Fig. 5. This kind of graph is also displayed from CFD simulations by Cieslicki and Piechna (2009). A general increasing trend can be noticed with a small decrease at the last $10 \%$ length, where the domain of calculation is ending in the middle of the last crossroad. Although the mixing process is clearly happening, the $M_{X}$ value does not reach the complete mixing considered as 85\% (cf. Section 2.4). In this regard, it is necessary to investigate how this $M_{X}$ value can be increased or decreased by the intrinsic flow conditions i.e., viscosity difference and/or flow-rate. Thus, the average mixing efficiency $M_{X}$ (Eq. 3) is calculated over the delimited red rectangle shown in Fig. 2, covering the whole area of the meshed circuit. It is plotted in Fig. 6 as a function of the channel Re number. In the case of water/water flow at $3.1 \mathrm{~mL} \cdot \mathrm{h}^{-1}$ the value of $M_{X}$ is 0.67, which is lower than the average of its local values (plotted in Fig. 5) due to an interval of concentration values being larger over the whole area than in a single $10 \%$ of its length. This average $M_{X}$ decreases when the flow rate is increasing. The tendency shown in Fig. 4 is thereby confirmed : the higher the flow rate, the less flow deviation through the crossroads and consequently, the worse the mixing performance. The mixing efficiency $M_{X}$ significantly decreases from 0.67 to 0.37 with the increasing flow rate from 3.1 to $23.8 \mathrm{~mL} \cdot \mathrm{h}^{-1}$ at each inlet. Another series of experiments using $11.1 \%$ glycerine in water was also carried out to test the effect of a higher viscosity, in the same range of flow rate. Its results are shown by red squares in Fig. 6 . The observed tendency is confirmed in another way: the increased viscosity decreases the Re number by about 20\% (cf. Tab. 2), thereby decreasing flow deviation from one stream to another. For the straight channel mixer the average mixing efficiency $M_{X}$ is around $20 \%$ below that of the meshed circuit device as shown in Fig. 6. To sum up, the meshed circuit with channel intersecting is significantly more efficient than the straight geometry 

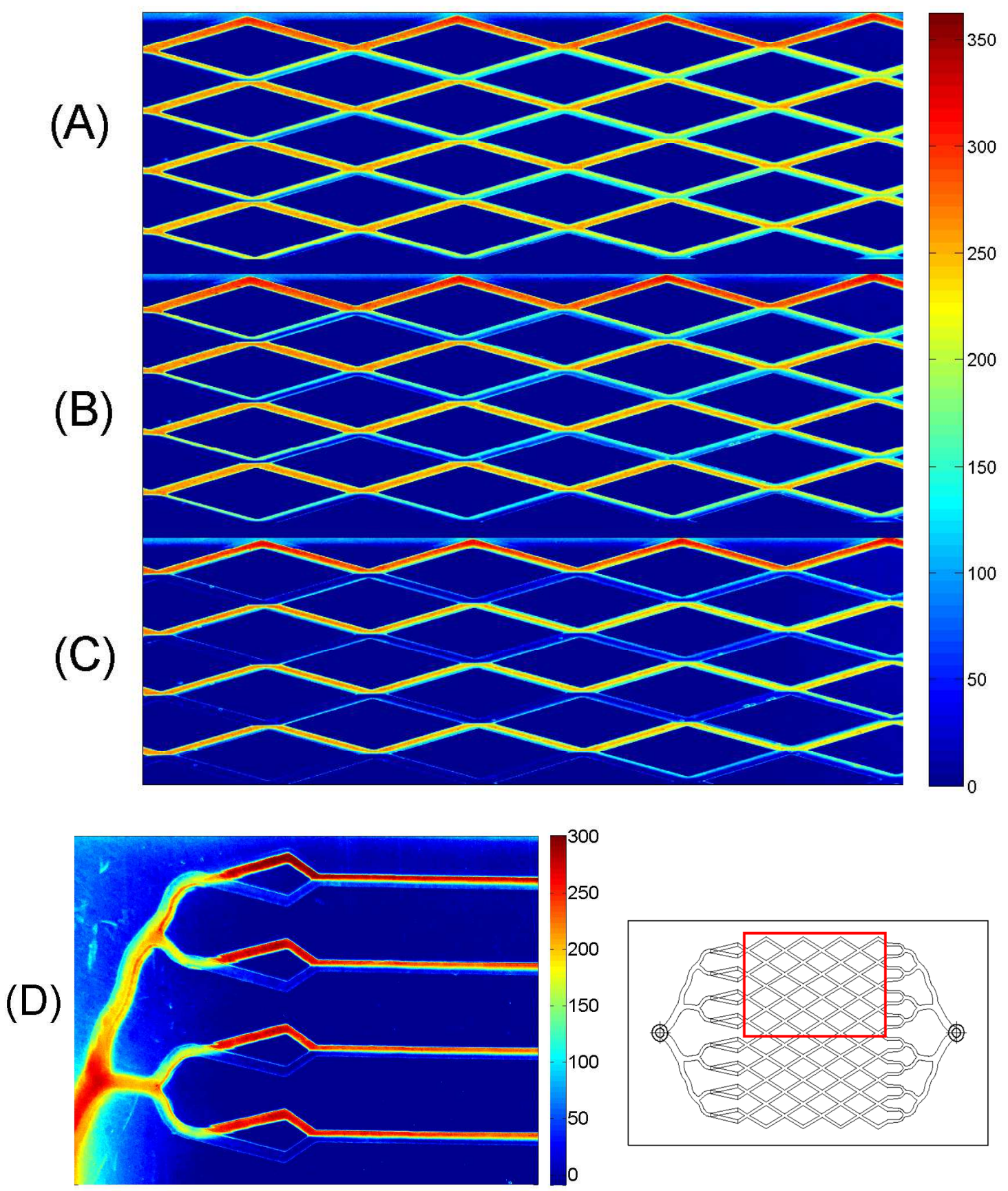

Figure 4: Concentration fields in $\left[\mathrm{mg} \cdot \mathrm{L}^{-1}\right]$. The flow goes from the left to the right. (A) : $4.3 \mathrm{~mL} \cdot \mathrm{h}^{-1}$ each. (B): $8.8 \mathrm{~mL} \cdot \mathrm{h}^{-1}$ each. (C): $18.8 \mathrm{~mL} \cdot \mathrm{h}^{-1}$ each. (D): Straight mixing channel, $7.5 \mathrm{~mL} \cdot \mathrm{h}^{-1}$ each. 
in terms of fluid mixing. Moreover, the higher merging of the streams at the crossroads instead of rebounds will enhance the mixing.

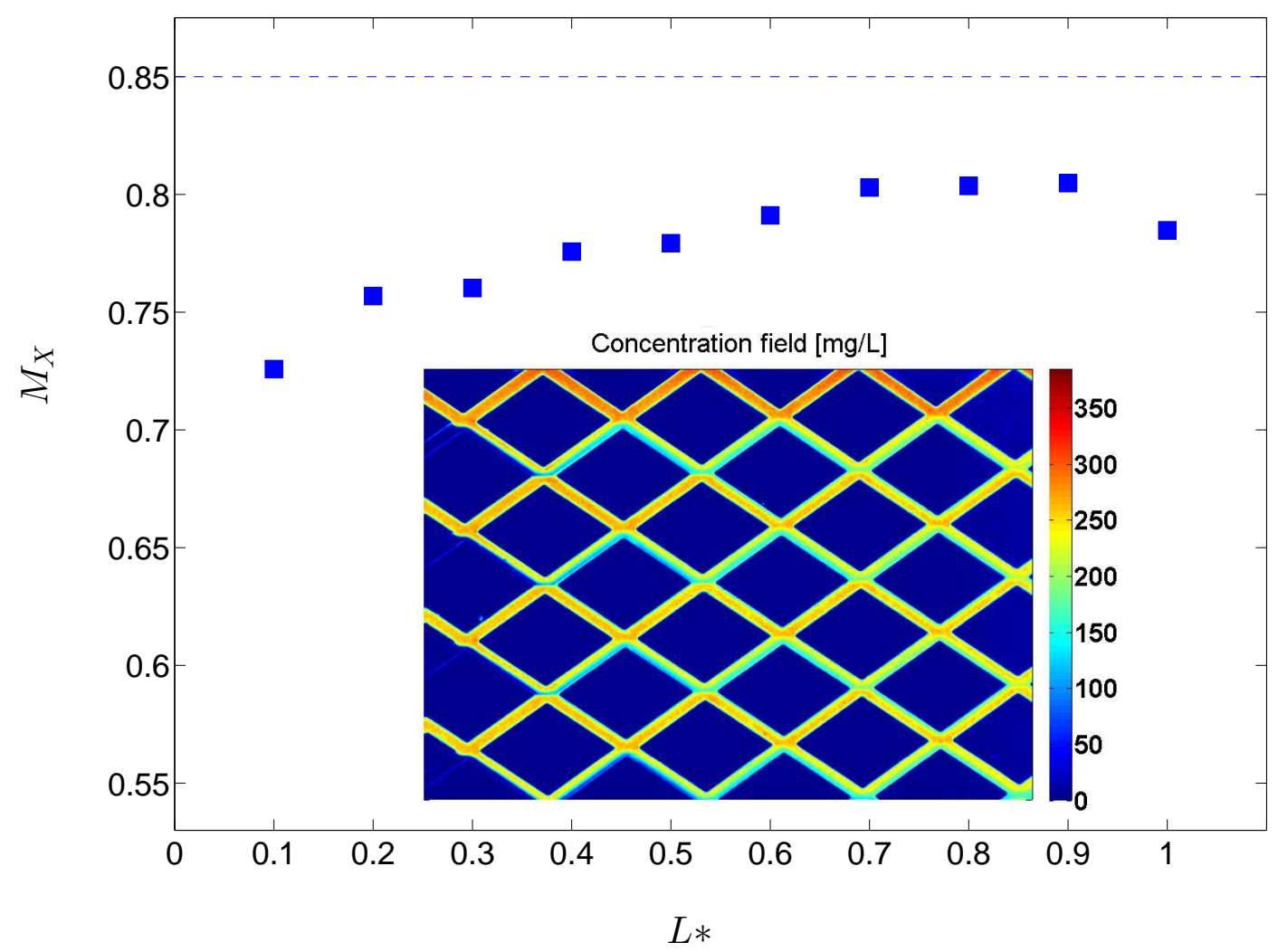

Figure 5: Progression of the local mixing efficiency along the length of the meshed network (3.1 $\mathrm{mL} \cdot \mathrm{h}^{-1}$ each). 


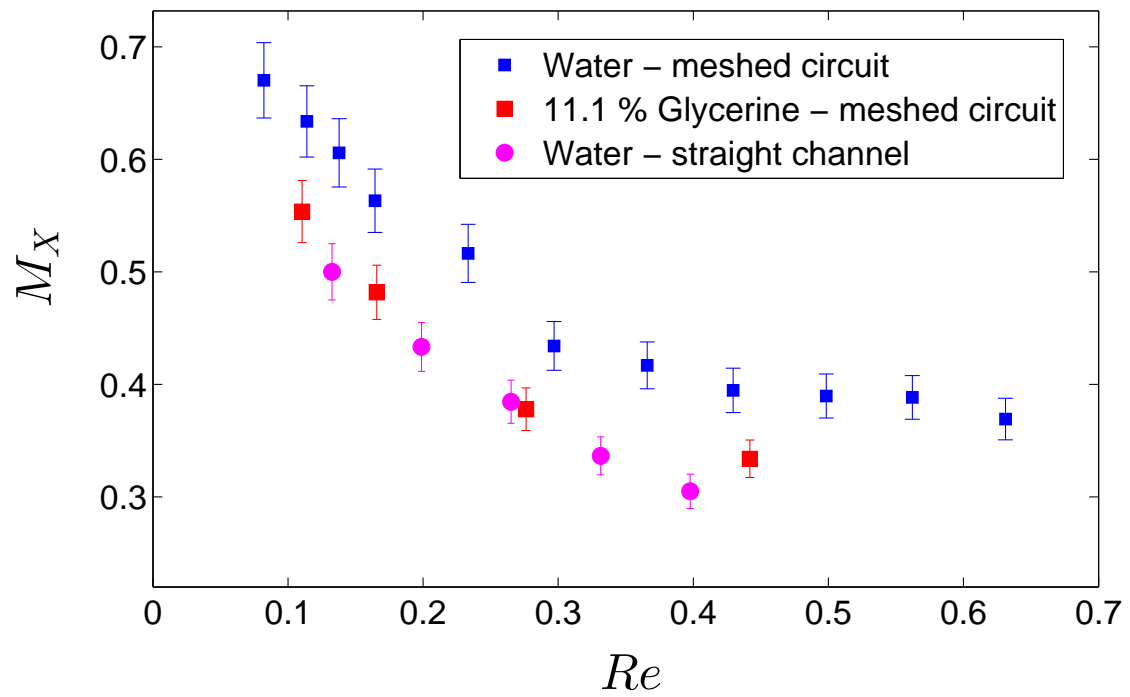

Figure 6: Average mixing efficiency $\left(M_{X}\right)$ plotted as a function of the channel Reynolds number in the meshed network. 


\subsection{Effect of the device position}

Although a small concentration of glycerine (0.1\% to $11.1 \%)$ is used here to adjust the viscosity, a significant effect was noticed in the vertical position : one fluid was flowing down into the other at the outlet of distributors, instead of continuing together into the meshed network. This problem vanished when the meshed circuit device was put in the horizontal position, as it was in all the experiments with different viscosities reported here. The buoyancy effect may provide an interpretation of this observation. Fig. 7 shows the progression of the mixing process through the meshed circuit both in the vertical and the horizontal positions using pure water at both inlets, within the same range of flow rate $\left(10,11.2\right.$ and $15 \mathrm{~mL} \cdot \mathrm{h}^{-1}$ at each inlet). In the vertical position, some areas in the first half of the meshed circuit are entirely transparent, resulting in an overestimated local $M_{X}$ that is not shown here. The comparison is clear: the progression of the mixing process is significantly reduced in the vertical position, whereas the horizontal position reaches complete mixing at $10 \mathrm{~mL} \cdot \mathrm{h}^{-1}$ (local $M_{X}$ exceeding $85 \%$ ).

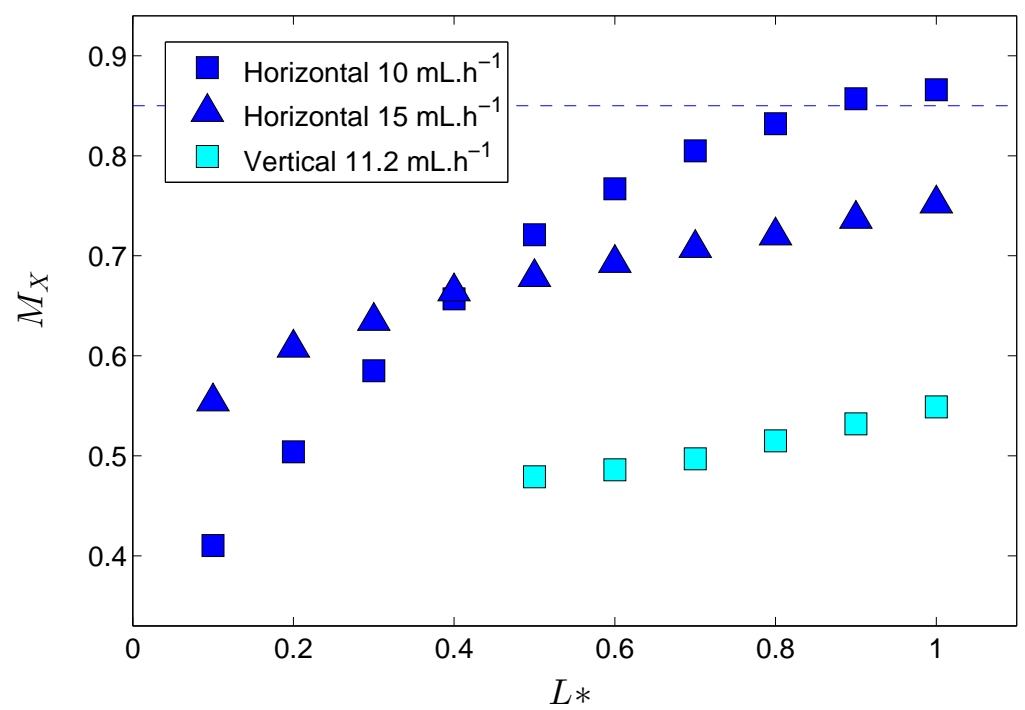

Figure 7: Comparison on the local mixing efficiency between horizontal and vertical position of the mixing device (pure water at both inlets). 


\subsection{Effect of viscosity difference}

To investigate the role of increased shear rate and flow deviation that are expected to enhance the meso-mixing, experiments were carried out feeding two liquids with different viscosities. In fact, when the two liquids are meeting at intersections, their viscosity difference augments the chance of flow deviation from one stream into another. This effect can be clearly seen on the concentration fields shown in Fig. 8, which were measured at the same flow rates $\left(15 \mathrm{~mL} \cdot \mathrm{h}^{-1}\right.$ at each side). The bottom picture using water with $0.25 \%$ vol. glycerine clearly shows that more amount of fluorescein enters into the other stream (pure water) compared to the blank situation (top image, pure water for both liquids). Flow deviation is visible even at such a low concentration of glycerine.

The progression of the mixing efficiency $M_{X}$ along the length of the meshed circuit is shown in Fig. 9. All the displayed cases have a flow rate of $10 \mathrm{~mL} \cdot \mathrm{h}^{-1}$ at both sides. Except for the case with $0.1 \%$ vol. glycerine, they all achieve almost complete mixing $\left(M_{X} \geq 0.85\right)$ at the end of the meshed circuit, before entering into the tree-like collector. In the cases with $2.5 \%$ and $5 \%$ vol. glycerine, most of the mixing process is done at the first crossroad just downstream the distributor, although the two streams continue their mixing afterwards. The highest increase in $M_{X}$, i.e. the most efficient mixing process is the case with $0.5 \%$ vol. glycerine. Its concentration field is also displayed as the inserted picture on Fig. 9. It shows a good progression of mixing, which is efficient from the first crossroads and converging towards a homogeneous concentration afterwards.

The factors that contribute to the enhanced mixing due to viscosity difference at the intersections are multiple, including different velocity profiles, higher shear rate, flow deviation, etc. First of all, the shear rate $\mu \frac{\partial u}{\partial x}$ is expected to be different at the meeting point of the two different streams having different viscosities. Secondly, the flow velocities are the same at both sides but the viscosities differ. At the first intersection, the difference between the two streams is quantified as their common flow velocity $V_{q}$ multiplied by the viscosity difference $\left(\mu_{1}-\mu_{2}\right)$. The average mixing efficiency $M_{X}$ over the whole meshed circuit as a function of $V_{q} \times\left(\mu_{1}-\mu_{2}\right)$ is plotted in Fig. 10 . The global trend is obvious: the $M_{X}$ increases with the increasing shear rate until it reaches a plateau from about $V_{q} \times\left(\mu_{1}-\mu_{2}\right) \simeq 3 \times 10^{-9} \mathrm{~kg} . \mathrm{s}^{-2}$. 


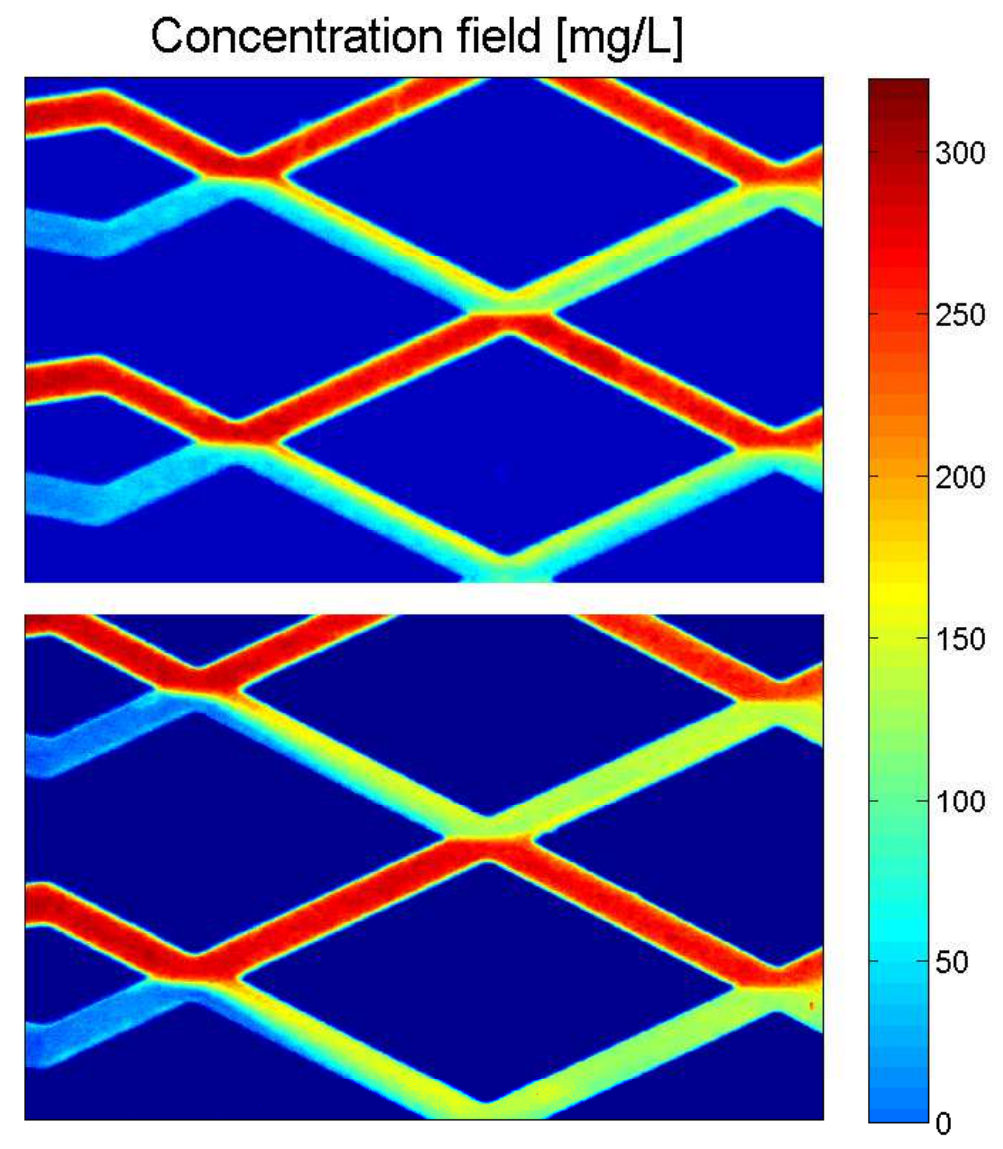

Figure 8: Concentration field at the first meeting point, $15 \mathrm{~mL} \cdot \mathrm{h}^{-1}$ each. (Top): pure water both; (Bottom): Water with $0.25 \%$ vol. glycerine, and pure water. 


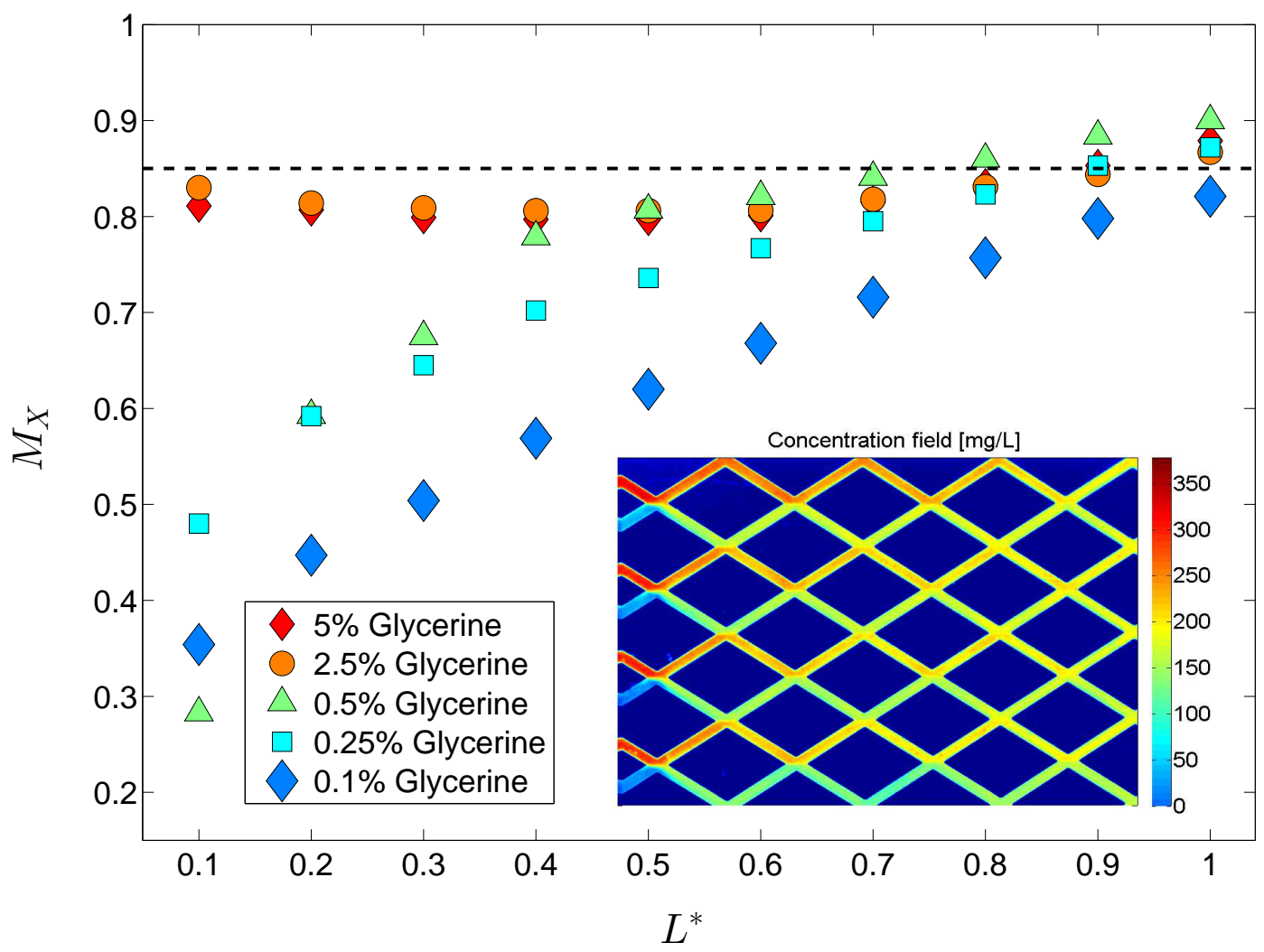

Figure 9: Progression of $M_{X}$ along the length of the meshed circuit - flow rate: $10 \mathrm{~mL} \cdot \mathrm{h}^{-1}$ at each inlet. The inserted concentration field is the case with $0.5 \%$ vol. glycerine. 


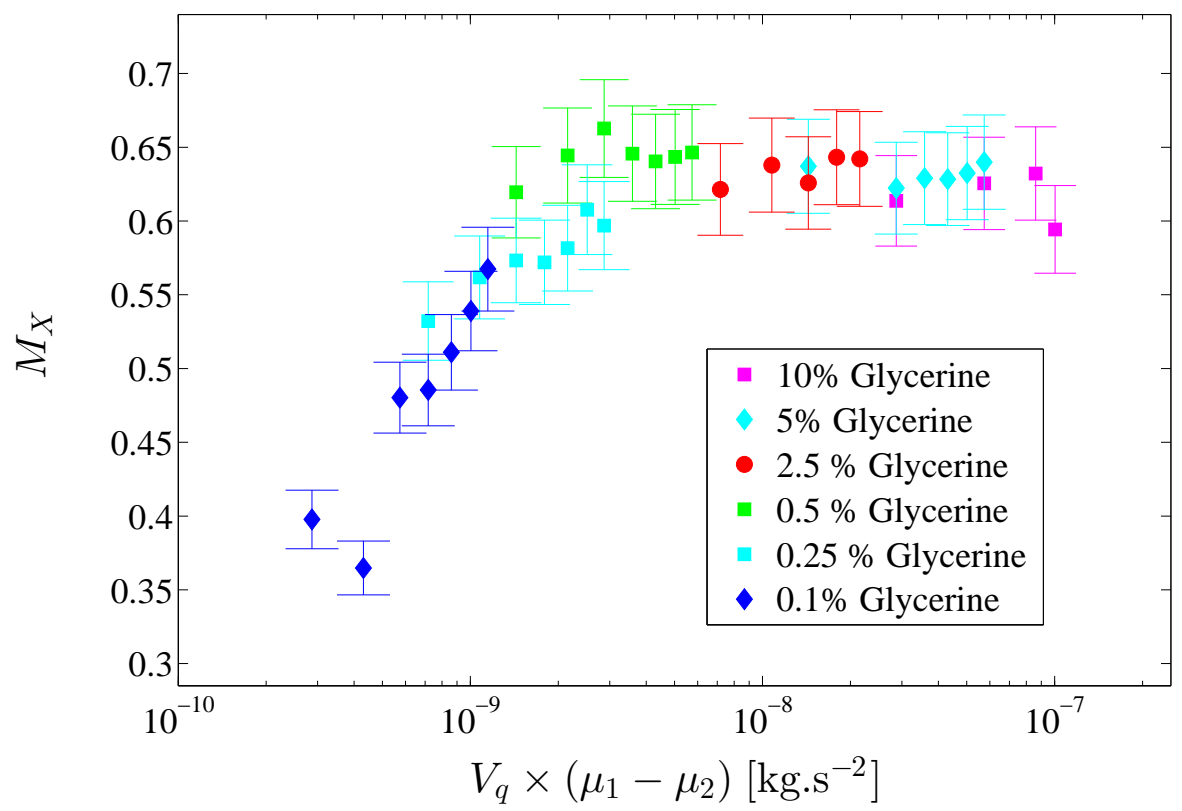

Figure 10: Average mixing efficiency of the meshed circuit using two liquids with different viscosities. 


\subsection{Exploring the flow deviation through simple CFD simulations}

Flow deviation caused by different viscosities can be properly described by means of CFD. In this extent, straightforward 3D simulations of the first crossroad (205,776 cells, see Fig. 11 and Tab. 3) were carried out with laminar model $(R e \leq 1)$, using ANSYS Fluent 18.1. The same gauge pressure (up to $0.25 \mathrm{~Pa}$ ) was applied to both inlets. The viscosity is calculated by the mixing law, and the gravity effect was not considered (horizontal position).

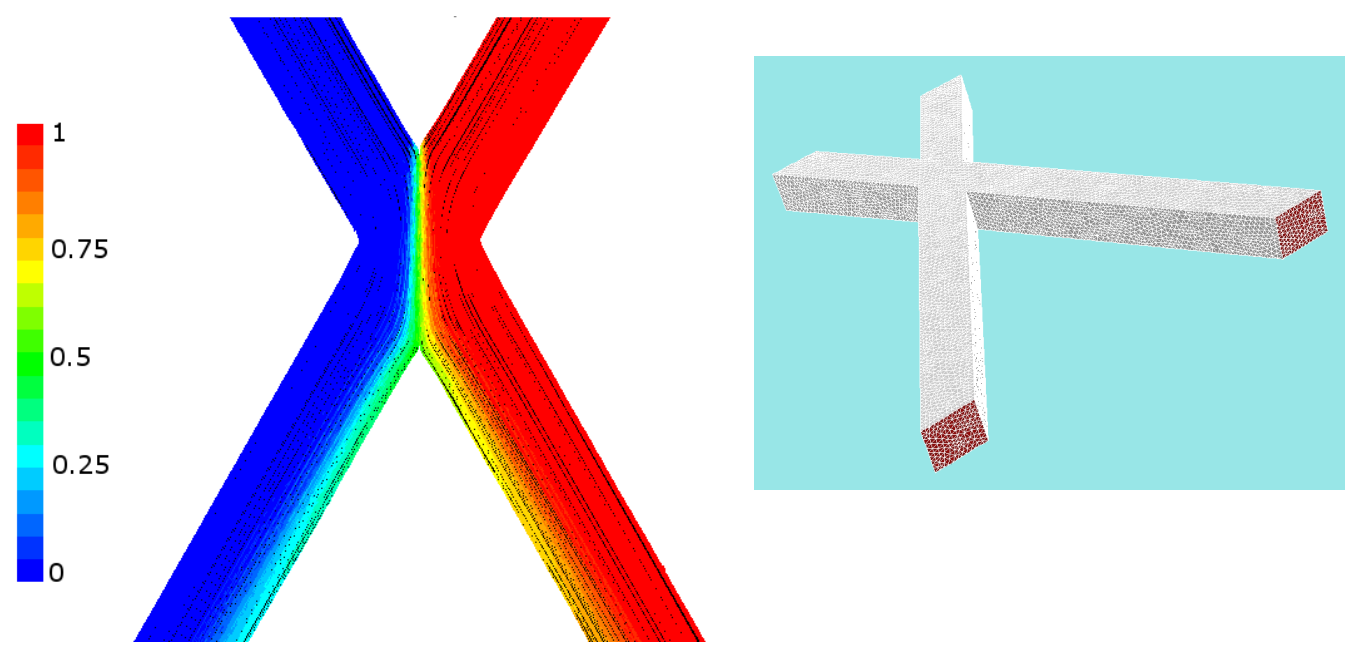

Figure 11: Mass fraction of one of the two liquids, along pathlines within the first crossroad (10\% vol. glycerine, $\left.2.59 \mathrm{~mL} \cdot \mathrm{h}^{-1}\right)$. (Inserted picture): the 3D mesh.

Exploiting the results of CFD simulations, it was seen that this flow deviation is accurately reported by $\Delta Q_{V}$ that is simply the difference between the flow rates at the outlets, divided by the minimum value of these two flow rates. Tab. 3 shows that deviation becomes significant (with $\Delta Q_{V}$ exceeding $1.5 \%)$ from $V_{q} \times\left(\mu_{1}-\mu_{2}\right) \simeq 3.10^{-9} \mathrm{~kg} . \mathrm{s}^{-2}$. This value matches the plateau of $M_{X}$ observed in the experiments Fig. 10, which confirms that flow deviation actually contributes to improve mixing efficiency, as it can also be seen in the concentration fields in Fig. 8.

Furthermore, these CFD simulations clearly show a significant flow deviation at the first crossroad, promoting the mixing from the very beginning of the meshed circuit, which is also experimentally confirmed at the first crossroad shown in Fig. 8. Deviation from the first crossroad can explain the different tendencies observed in the concentration profiles in Figs. 5 and 9 along an increasing difference in viscosity: even in the vertical (Fig. 5) or 


\begin{tabular}{|c|c|c|c|c|}
\hline$\mu_{1}-\mu_{2}$ & Glycerine & Flow rate & $V_{q} \times\left(\mu_{1}-\mu_{2}\right)$ & $\Delta Q_{V}$ \\
\hline Pa.s & \% Vol. & $\mathrm{mL.h}^{-1}$ & $\mathrm{~kg} . \mathrm{s}^{-2}$ & $\%$ \\
\hline $9.10^{-5}$ & $10 \%$ & 2.59 & $5.62 \times 10^{-8}$ & $7.01 \%$ \\
\hline $4.5 .10^{-5}$ & $5 \%$ & 2.65 & $2.87 \times 10^{-8}$ & $3.51 \%$ \\
\hline $4.5 .10^{-5}$ & $5 \%$ & 0.53 & $5.75 \times 10^{-9}$ & $3.20 \%$ \\
\hline $2.25 .10^{-5}$ & $2.50 \%$ & 0.54 & $2.91 \times 10^{-9}$ & $1.60 \%$ \\
\hline $2.25 .10^{-5}$ & $2.50 \%$ & 0.27 & $1.45 \times 10^{-9}$ & $1.42 \%$ \\
\hline $9.10^{-6}$ & $0.50 \%$ & 0.27 & $5.85 \times 10^{-10}$ & $0.56 \%$ \\
\hline $9.10^{-7}$ & $0.05 \%$ & 0.27 & $6.53 \times 10^{-11}$ & $0.05 \%$ \\
\hline
\end{tabular}

Table 3: CFD simulation results of a single crossroad at the beginning of the meshed circuit.

horizontal (Fig. 9) positions, the mixing index $M_{X}$ is progressively increasing from $30 \%$ to $85 \%$ when the difference in viscosity is tiny (0.1\% Glycerine) or null, but $M_{X}$ starts around $80 \%$ when the difference in viscosity is high (see the cases with $2.5 \%$ and $5 \%$ glycerine Fig. 9). This also indicates that the length of the meshed circuit is also a parameter subject to optimization: only several crossovers are already sufficient in case of large viscosity difference, making the mixing device much more compact. 


\subsection{Pressure drop}

The pressure drop was measured (Fig. 2) with the nature-inspired mixer in the uprising position. Due to the low flow rate, it depends more on the water height than the flow rate. In the worst case with $20 \mathrm{~mL} \cdot \mathrm{h}^{-1}$ at both inlets, its value was less than $2000 \mathrm{~Pa}$ using water, and less than $3000 \mathrm{~Pa}$ using the most viscous liquid of the present study, i.e., water with $11.1 \%$ glycerine. This value was not seen as surprising, since the circuit is $12 \mathrm{~cm}$ long and $10 \mathrm{~cm}$ of water height gives $981 \mathrm{~Pa}$ of hydrostatic pressure. The void volume for fluids in the mixer $V_{i n}$ is $2 \mathrm{ml}$, so the energy dissipation rate $W_{q}$ (Eq. 5) is less than $1.4 \times 10^{-2} \mathrm{~W} \cdot \mathrm{kg}^{-1}$ using water. Bothe et al. (2006) obtain from numerical simulations, at a higher velocity of $0.1 \mathrm{~m} . \mathrm{s}^{-1}$, less than $2.10^{-1} \mathrm{~W} \cdot \mathrm{kg}^{-1}$ in a T-shaped micro-mixer.

$$
W_{q}=\frac{Q_{V} \Delta P}{\rho V_{\text {in }}} \longrightarrow\left[W . k g^{-1}\right]
$$

The order of magnitude of the measured pressure drop is compared with the relevant studies in the literature. Chen et al. (2016) give a CFD-computed pressure drop through square-wave, zig-zag and multi-wave channels that are around $1 \mathrm{~mm}$ large and $5 \mathrm{~cm}$ long of [0-5000] Pa for $R e \leq 50$. Shah et al. (2019) give results of numerical simulations within Y-shaped split-andrecombine micro-mixer that are less than $2000 \mathrm{~Pa}$ with $R e$ being 0.5 and 10, within a $300 \mu m \times 200 \mu m$ section over $30 \mathrm{~mm}$ length. In the present case with $R e \leq 1$, the pressure drop of $3000 \mathrm{~Pa}$ is regarded as acceptable for biochemical applications. 


\section{Conclusions and prospects}

A detailed, in-depth investigation of mixing throughout a nature-inspired mixer based on the split-intersect-recombine principle was carried out. A non-intrusive, easy-to-implement measurement of the concentration field of fluorescein was successfully implemented. Main findings of this study can be highlighted as follows.

- Mixing performance is improved by deviation of a stream into the other one, and this is why the crossroads of the meshed circuit are beneficial. The residence time through the straight channels is not long enough for sufficient molecular diffusion.

- Acceptable pressure drop and the resulting energetic cost are found, aiming at possible applications such as biochemical analysis or nanomaterials synthesis.

- Flow deviation is triggered by adjusting viscosity at one side. An optimum performance was noticed in the form of a plateau of the estimated shear stress at the first crossroad, as confirmed by CFD simulations. Complete mixing is achieved using a tiny (0.5\%) addition of glycerine at one side.

- As prospects, further geometrical considerations such as obstacles or other topologies could be expected to adapt the present mixing device to higher Reynolds numbers (in the order of 50). Future studies should also focus on increasing the compactness of the meshed circuit geometry. Intrinsic fluid properties like viscosity should also be taken into account to solve a wide range of industrial situations within the laminar flow regime.

\section{Acknowledgment}

This work is supported by the French Ministry of Europe and Foreign Affairs (Ministère de l'Europe et des Affaires Étrangères) through the PHC Xu Guangqi program (No.45614RM, 2020). The authors gratefully acknowledge the support from École Centrale de Nantes (ECN) with the INJECTOMAT Fresenius Syringe pusher, and Mr. Gwenaël Biotteau (LTeN) for manufacturing the mixing device. 
Afzal, A., Kim, K.-Y., 2015. Convergent divergent micromixer coupled with pulsatile flow. Sensors and Actuators B: Chemical 211, 198 - 205.

Alemàn, E., Lamichhane, R., Rueda, D., 2008. Exploring rna folding one molecule at a time. Curr. Opin. Chem. Biol. 12, 647 - 654.

Ansari, M. A., Kim, K.-Y., 2010. Mixing performance of unbalanced split and recombine micromixers with circular and rhombic sub-channels. Chemical Engineering Journal 162 (2), 760 - 767.

Aubin, J., Ferrando, M., Jiricny, V., 2010. Current methods for characterising mixing and flow in microchannels. Chemical Engineering Science 65 (6), $2065-2093$.

Barber, R., Emerson, D., 2008. Optimal design of microfluidic networks using biologically inspired principles. Microfluidics and Nanofluidics 4, 179 - 191.

Bayareh, M., Ashani, M. N., Usefian, A., 2020. Active and passive micromixers: A comprehensive review. Chemical Engineering and Processing - Process Intensification 147, 107771.

Bothe, D., Stemich, C., Warnecke, H.-J., 2006. Fluid mixing in a t-shaped micro-mixer. Chemical Engineering Science 61 (9), 2950 - 2958.

Chen, J. J., Chen, C. H., Shie, S. R., 2011. Optimal designs of staggered dean vortex micromixers. International Journal of Molecular Science 12, 3500-3524.

Chen, X., Li, T., 2017. A novel passive micromixer designed by applying an optimization algorithm to the zigzag microchannel. Chemical Engineering Journal 313, 1406 - 1414.

URL http://www.sciencedirect.com/science/article/pii/ S138589471631614X

Chen, X., Li, T., Li, X., 2016. Numerical research on shape optimization of microchannels of passive micromixers. IEEE Sensors Journal 16 (17), 6527-6532.

Chen, X., Li, T., Zeng, H., Hu, Z., Fu, B., 2016. Numerical and experimental investigation on micromixers with serpentine microchannels. International Journal of Heat and Mass Transfer 98, 131 - 140. 
Chen, X., Shen, J., 2017. Numerical analysis of mixing behaviors of two types of e-shape micromixers. International Journal of Heat and Mass Transfer 106, $593-600$.

URL http://www.sciencedirect.com/science/article/pii/ S0017931016318348

Chen, X., Wang, X., 2015. Optimized modular design and experiment for staggered herringbone chaotic micromixer. International Journal of Chemical Reactor Engineering 13(3), 305-309.

Ching, T., Toh, Y.-C., Hashimoto, M., 2019. Fabrication of complex 3d fluidic networks via modularized stereolithography. Advanced Engineering Materials 22 (3), 1901109.

Choi, S., Song, S., Choi, C., Park, J., 2009. Hydrophoretic sorting of micrometer and submicrometer particles using anisotropic microfluidic obstacles. Analytical Chemistry 81, 50-55.

Cieslicki, K., Piechna, A., 2009. Investigations of mixing process in microfluidic manifold designed according to biomimetic rule. Lab Chip 9, 726-732.

deMello, J., deMello, A., 2004. Focus microscale reactors: nanoscale products. Lab Chip 4, $11 \mathrm{~N}-15 \mathrm{~N}$.

Egawa, T., Durand, J., Hayden, E., Rousseau, D., Yeh, S.-R., 2009. Design and evaluation of a passive alcove-based microfluidic mixer. Analytical Chemistry 81, 16221627.

Erbacher, C., Bessoth, F. G., Busch, M., Verpoorte, E., Manz, A., Jun 1999. Towards integrated continuous-flow chemical reactors. Microchimica Acta 131 (1), 19-24.

Gambin, Y., Simonnet, C., VanDelinder, V., Deniz, A., Groisman, A., 2010. Ultrafast microfluidic mixer with three-dimensional flow focusing for studies of biochemical kinetics. Lab on a Chip 10, 598-609.

Ghanem, A., Lemenand, T., Valle, D. D., Peerhossaini, H., 2014. Static mixers: Mechanisms, applications, and characterization methods a review. Chemical Engineering Research and Design 92 (2), 205 - 228. 
Gray, B., Jaeggi, D., Mourlas, N., Drieenhuizen, B., Williams, K., Maluf, N., Kovacs, 1999. Novel interconnection technologies for integrated microfluidic systems. Sens. Actuators 77, $57-65$.

Guo, X., Fan, Y., Luo, L., 2013. Mixing performance assessment of a multichannel mini heat exchanger reactor with arborescent distributor and collector. Chemical Engineering Journal 227, 116 - 127.

Hertzog, D., Ivorra, B., Mohammadi, B., Bakajin, O., Santiago, J., 2006. Optimization of a microfluidic mixer for studying protein folding kinetics. Anal. Chem. 78, 4299 - 4306.

Hsieh, S.-S., Lin, J.-W., Chen, J.-H., 2013. Mixing efficiency of y-type micromixers with different angles. International Journal of Heat and Fluid Flow 44, 130 - 139.

Huang, J.-H., Kim, J., Agrawal, N., Sudarsan, A. P., Maxim, J. E., Jayaraman, A., Ugaz, V. M., 2009. Rapid fabrication of bio-inspired 3d microfluidic vascular networks. Advanced Materials 21 (35), 3567-3571.

Jang, M., Kwon, Y. J., Lee, N. Y., 2015. Non-photolithographic plastic-moldbased fabrication of cylindrical and multi-tiered poly(dimethylsiloxane) microchannels for biomimetic lab-on-a-chip applications. RSC Adv. 5, 100905-100911.

Lee, C.-Y., Wang, W.-T., Liu, C.-C., Fu, L.-M., 2016. Passive mixers in microfluidic systems: A review. Chemical Engineering Journal 288, 146 160 .

Lee, J.-S., 2000. Distinguished lecture: Biomechanics of the microcirculation, an integrative and therapeutic perspective. Annals of Biomedical Engineering $28,1-13$.

Lee, M. G., Choi, S., Park, J.-K., 2009. Three-dimensional hydrodynamic focusing with a single sheath flow in a single-layer microfluidic device. Lab Chip 9, 3155-3160.

Li, Y., Zhang, D., Feng, X., Xu, Y., Liu, B.-F., 2012. A microsecond microfluidic mixer for characterizing fast biochemical reactions. Talanta 88, $175-180$. 
Mao, X., Juluri, B., Lapsley, M., Stratton, Z., Huang, T., 2010. Milliseconds microfluidic chaotic bubble mixer. Microfluid. Nanofluid. 8, 139 - 144.

Neerincx, P., Denteneer, R., Peelen, S., Meijer, H., 2011. Compact mixing using multiple splitting, stretching, and recombining flows. Macromol. Mater. Eng. 296, 349 - 361.

Ottino, J., 1989. The kinematics of mixing: stretching, chaos, and transport. Cambridge University Press.

Parnis, J. M., Oldham, K. B., 2013. Beyond the beerlambert law: The dependence of absorbance on time in photochemistry. Journal of Photochemistry and Photobiology A: Chemistry 267, 6-10.

Roder, H., Maki, K., Cheng, H., 2006. Early events in protein folding explored by rapid mixing methods. Chem. Rev. 106, 1836 - 1861.

Schwertfirm, F., Gradl, J., Schwarzer, H., Peukert, W., Manhart, M., 2007. The low reynolds number turbulent flow and mixing in a confined impinging jet reactor. International Journal of Heat and Fluid Flow 28, 1429 1442 .

Shah, I., Kim, S. W., Kim, K., Doh, Y. H., Choi, K. H., 2019. Experimental and numerical analysis of $\mathrm{y}$-shaped split and recombination micro-mixer with different mixing units. Chemical Engineering Journal 358, 691 - 706.

Suh, Y., Kang, S., 2010. A review on mixing in microfluidics. Micromachines, $82-111$.

Tarlet, D., Fan, Y., Roux, S., Luo, L., 2014. Entropy generation analysis of a mini heat exchanger for heat transfer intensification. Experimental Thermal and Fluid Science 53, 119 - 126.

Tondeur, D., Fan, Y., Commenge, J., Luo, L., 2011a. Flow and pressure distribution in linear discrete ladder-type fluidic circuits: An analytical approach. Chemical Engineering Science 66 (12), 2658 - 2586.

Tondeur, D., Fan, Y., Commenge, J., Luo, L., 2011b. Uniform flows in rectangular lattice networks 66, $5301-5312$. 
Tondeur, D., Fan, Y., Luo, L., 2009. Constructal optimization of arborescent structures with flow singularities. Chemical Engineering Science 64 (18), $3968-3982$.

Wang, L., Fan, Y., Luo, L., 2010. Heuristic optimality criterion algorithm for shape design of fluid flow. Journal of Computational Physics 229, 8031 -8044 .

Wang, L., Fan, Y., Luo, L., 2014. Lattice boltzmann method for shape optimization of fluid distributor. Computers and Fluids 94, $49-57$.

Wang, S., 2007. Distribution optimization for plate-fin catalytic combustion heat exchanger. Chemical Engineering Journal 131, 171-179.

Woldemariam, M., Filimonov, R., Purtonen, T., Sorvari, J., Koiranen, T., Eskelinen, H., 2016. Mixing performance evaluation of additive manufactured milli-scale reactors. Chemical Engineering Science 152, 26 - 34.

Yue, J., Boichot, R., Luo, L., Gonthier, Y., Chen, G., Yuan, Q., 2010. Flow distribution and mass transfer in a parallel microchannel contactor integrated with constructal distributors. AIChE Journal 56 (2), 298-317.

Zhou, P., Tarlet, D., Fan, Y., Hu, X., Luo, L., 2018. Water-in-oil emulsification in a bifurcated tree-like network: Flow distribution properties and their impact on the emulsion polydispersity. Chemical Engineering Research and Design 134, $420-433$.

Zhou, P., Tarlet, D., Wei, M., Fan, Y., Luo, L., 2017. Novel multi-scale parallel mini-channel contactor for monodisperse water-in-oil emulsification. Chemical Engineering Research and Design 121, 233 - 244. 